This item was submitted to Loughborough's Research Repository by the author.

Items in Figshare are protected by copyright, with all rights reserved, unless otherwise indicated.

\title{
The spectral variation effects on energy yield of optimized multi-junction solar cell
}

PLEASE CITE THE PUBLISHED VERSION

http://dx.doi.org/10.1109/PVSC.2009.5411143

PUBLISHER

(C) IEEE

VERSION

VoR (Version of Record)

LICENCE

CC BY-NC-ND 4.0

REPOSITORY RECORD

Qiu, Yingning, A.W. Clarke, Thomas R. Betts, and Ralph Gottschalg. 2019. "The Spectral Variation Effects on Energy Yield of Optimized Multi-junction Solar Cell”. figshare. https://hdl.handle.net/2134/8200. 
This item was submitted to Loughborough's Institutional Repository (https://dspace.lboro.ac.uk/) by the author and is made available under the following Creative Commons Licence conditions.

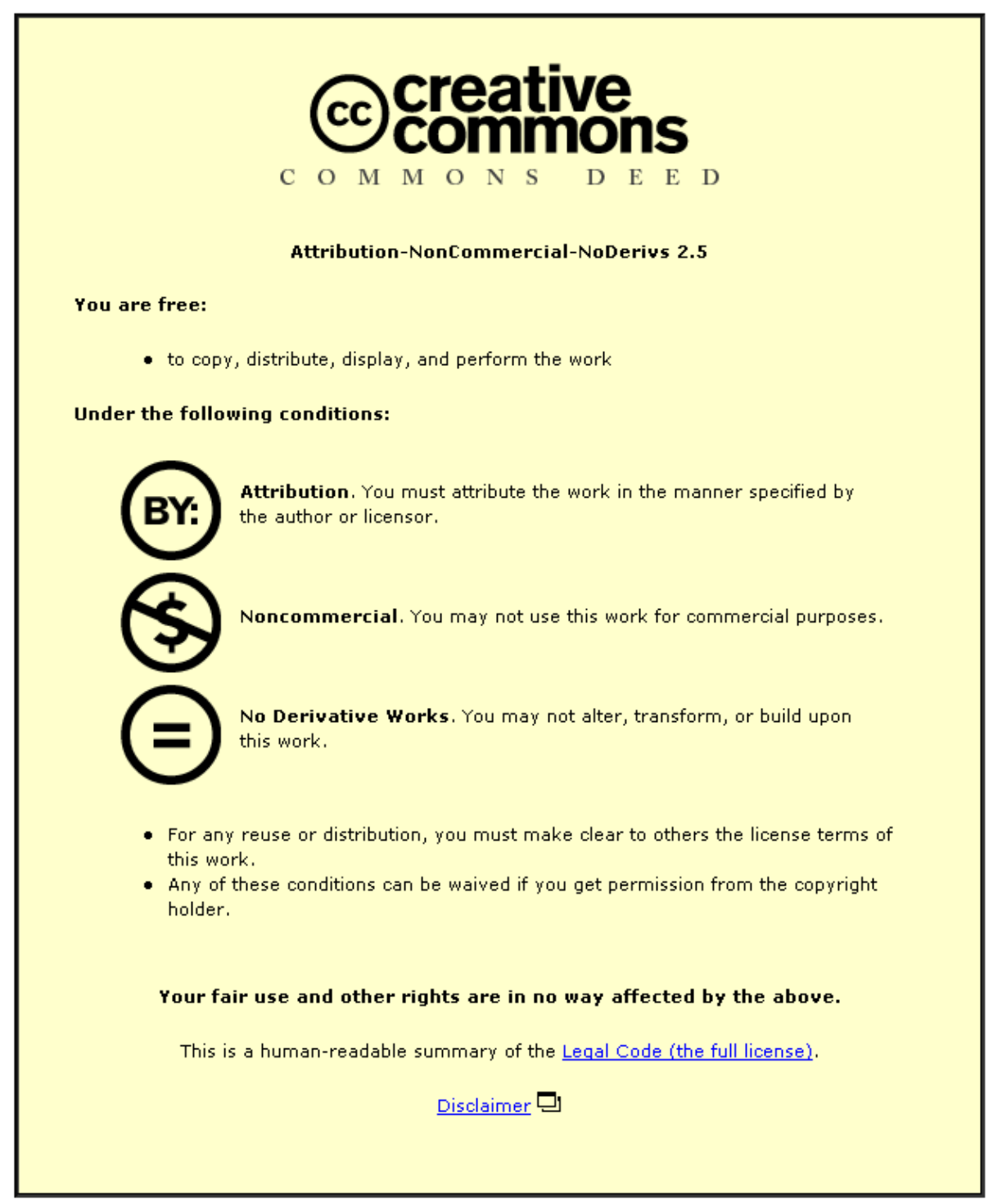

For the full text of this licence, please go to: http://creativecommons.org/licenses/by-nc-nd/2.5/ 


\title{
THE SPECTRAL VARIATION EFFECTS ON ENERGY YIELD OF OPTIMIZED MULTI- JUNCTION SOLAR CELL
}

\author{
Y.N. Qiu, A.W. Clarke, T. R. Betts, R. Gottschalg \\ Centre for Renewable Energy Systems Technology (CREST), Department of Electronic and Electrical Engineering, \\ Loughborough University, Loughborough, Leicestershire, LE11 3TU, United Kingdom \\ Tel.: +44 1509 635336, Fax: +44 1509 635301, Email: Y.Qiu@lboro.ac.uk
}

\begin{abstract}
The effect of spectral variations on the maximal achievable efficiency of multi-junction solar cells is investigated in this paper. The energy yield rather than power rating are considered here. With the optimized band gaps under STC the average and annual efficiency for spectral irradiances measured at CREST in a wavelength range from $310-1710 \mathrm{~nm}$ is calculated. The material band gap optimised for the measured average annual spectrum and for STC spectrum are compared. The annual efficiency and the annual yield of multi-junction solar cells are calculated. It shows that optimum material band gaps shift for a spectrum deviates from AM1.5 which indicates that the spectral effects should be taken into account to optimize multi-junction solar cell structure and system design. The energy generated in Loughborough is calculated for one year and it is shown that the performance ratio of multi-junction solar cells optimized under realistic condition is significantly reduced.
\end{abstract}

\section{INTRODUCTION}

It is conceptually agreed that by increasing the number of junctions in a solar cell, the efficiency of a single cell can be improved because it utilize broader range of the solar spectrum. A number of theoretical works has been done to investigate the efficiency limit of multijunction solar cell, which can be over $60 \%$ [1]. Most of the calculations are based either on black body spectra or on the AM1.5 G spectrum used in the standard test conditions (STC). However, little consideration is given to naturally occurring spectral variations. Furthermore, normally the power rating and not the energy yield is considered [2], as the power rating is easier to calculate. The power rating is, however, not what describes the usefulness or costeffectiveness of PV. This paper is quantifying the losses incurred due to optimisation to AM1.5G in idealised multijunction solar cells. The efficiency limits are re-evaluated based on realistic spectral operating conditions. This investigation is useful to optimize the PV system design of multi-junction solar cells for global location.

A model is derived for the calculation of power of a multijunction for a given spectral environment. This is then compared to standard theory and applied further to realistic spectra.
Firstly, the optimized band gaps under STC and black body conditions are obtained for single and multi-junction solar cells. The model are validated by the comparison made between the calculated maximum efficiencies to that reported in the literatures with other models. Secondly, the optimized material band gaps for average spectral irradiances measured at CREST in a wavelength range from $310-1710 \mathrm{~nm}$ is calculated and the average and annual efficiencies with the band gap under STC and under realistic spectrum are compared. Then the annual yield and the performance ratio with different optimized band gap with the realistic spectrum are compared.

\section{THEORETICAL DEVELOPMENT}

An appropriate theoretical model to calculate the efficiency of a multi-junction solar cell is developed and the common assumptions are reviewed. However, it has been pointed out that the consistency of the methodology is more important than the choice of the model when comparing different spectral effects to the efficiency calculation [3]. The equivalent circuit model which is derived through carrier transport theory and assumes the junction as an ideal diode is adopted, in which the parameters, saturation dark current and open circuit voltage, are calculated based on Shockley-Queisser approach and Kiess Model respectively [4,5]. In the case of multi-junction solar cells, photons with energy above the band gap will be absorbed and photons with energies below that will pass through the material unperturbed. Thus junctions with wider band gaps sit on top of those with lower band gaps.

The short circuit current of the multi-junction solar cell is calculated with:

$$
J_{s c-n}=\int_{\lambda_{n-1}}^{\lambda_{n}} S R_{n} E(\lambda) d \lambda
$$

where $n$ is the number (index) of the junction in a single cell, SR is the spectral response of that junction and $E$ is the spectrum being investigated. The integration wavelength range from $\lambda_{n-1}$ and $\lambda_{n}$ are determined by the band gap of the $n$-th junction, i.e. its spectrally responsive region. In this paper for the simplicity, it is assumed that the SR equals unity for the whole response wavelength range for $n$-th junction. Multi-junctions are then simulated in which the top junction acts as a selective filter for the 
junction below and thus modifies the incident irradiance. The overall short circuit current is limited by the lowest short circuit current of all the junctions. Assuming the fill factor is unity, the output power of a solar cell is the product of short circuit current and the open circuit voltage. The open circuit voltage is calculated with formula (2)-(3):

$$
\begin{aligned}
& J_{0 n}=C^{*} \exp \left(\frac{-E_{G, n}}{k T}\right) \\
& V_{o c}=\frac{k T}{q} \ln \left(\frac{J_{s c n}}{J_{0 n}}+1\right)
\end{aligned}
$$

As shown in equation (2), the higher the material band gap, the lower the dark saturation current and thus the higher the open circuit voltage as predicted by formula (3). The overall open circuit voltage is the sum of the subsequent junctions of a cell. The more junctions are in the solar cell, the higher the open circuit voltage will be. However the short circuit current is limited by the lowest one of all the junctions. Therefore, the power output is determined by the product of $\mathrm{J}_{\mathrm{SC}}$ and the $\mathrm{V}_{\mathrm{oc}}$.

The optimized energy band gap for a black body with $5760 \mathrm{~K}$ temperature, AM1.5, AM1.5 from $310 \mathrm{~nm}$ to $1710 \mathrm{~nm}$ and for the average spectrum measure at Loughborough from Sept. 2003 to Aug. 2004, respectively, are compared and listed in table I. The wavelength range was chosen because the spectral measurement system at CREST was capable of measuring in the given range. Here, $\eta$ is the efficiency limit for these two spectra with corresponding Egn ( $n=1$ to 6$)$ which is material band gap specified in different layers. Comparing with the result in [6], the optimum band gap list here are reasonable and valid.

Table I Comparison of optimized efficiency for different irradiance conditions.

Black Body Irradiance (APE=1.45eV)

\begin{tabular}{|l|l|l|l|l|l|l|l|}
\hline $\mathrm{n}$ & $\begin{array}{l}\eta \\
(\%)\end{array}$ & $\mathrm{E}_{\mathrm{G}, 1}$ & $\mathrm{E}_{\mathrm{G}, 2}$ & $\mathrm{E}_{\mathrm{G}, 3}$ & $\mathrm{E}_{\mathrm{G}, 4}$ & $\mathrm{E}_{\mathrm{G}, 5}$ & $\mathrm{E}_{\mathrm{G}, 6}$ \\
\hline 1 & 30.9 & 1.31 & -- & -- & -- & -- & -- \\
\hline 2 & 42.2 & 1.66 & 1.01 & -- & -- & -- & -- \\
\hline 3 & 48.2 & 1.91 & 1.32 & 0.90 & -- & -- & -- \\
\hline 4 & 51.9 & 2.05 & 1.49 & 1.10 & 0.77 & -- & -- \\
\hline 5 & 54.3 & 2.24 & 1.71 & 1.35 & 1.07 & 0.81 & -- \\
\hline 6 & 55.9 & 2.25 & 1.72 & 1.37 & 1.09 & 0.84 & 0.59 \\
\hline
\end{tabular}

AM1.5 Irradiance (STC) (APE=1.49eV)

\begin{tabular}{|l|l|l|l|l|l|l|l|}
\hline $\mathrm{n}$ & $\begin{array}{l}\eta \\
(\%)\end{array}$ & $\mathrm{E}_{\mathrm{G}, 1}$ & $\mathrm{E}_{\mathrm{G}, 2}$ & $\mathrm{E}_{\mathrm{G}, 3}$ & $\mathrm{E}_{\mathrm{G}, 4}$ & $\mathrm{E}_{\mathrm{G}, 5}$ & $\mathrm{E}_{\mathrm{G}, 6}$ \\
\hline 1 & 33.5 & 1.34 & -- & -- & -- & -- & -- \\
& & $\begin{array}{l} \pm \\
\%\end{array}$ & & & & & \\
\hline 2 & 45.0 & 1.63 & 0.98 & -- & -- & -- & -- \\
& & \pm 2 & \pm 4 & & & & \\
& & $\%$ & $\%$ & & & & \\
\hline 3 & 51.1 & 1.90 & 1.38 & 0.96 & -- & -- & -- \\
\hline
\end{tabular}

\begin{tabular}{|l|l|l|l|l|l|l|l|}
\hline & & \pm 0. & \pm 1 & \pm 2 & & & \\
& & $5 \%$ & $\%$ & $\%$ & & & \\
\hline 4 & 54.4 & 2.0 & 1.49 & 1.12 & 0.74 & -- & -- \\
& & \pm 0. & \pm 0. & \pm 0. & \pm 1. & & \\
& & 06 & $2 \%$ & 03 & $0 \%$ & & \\
& & $\%$ & & $\%$ & & & \\
\hline 5 & 56.7 & 2.14 & 1.67 & 1.33 & 1.00 & 0.73 & -- \\
& & \pm 1. & \pm 1. & \pm 3. & \pm 2. & \pm 1. & \\
& & $7 \%$ & $2 \%$ & $7 \%$ & $0 \%$ & $0 \%$ & \\
\hline 6 & 58.8 & 2.23 & 1.78 & 1.46 & 1.19 & 0.96 & 0.70 \\
& & \pm 0. & \pm 0. & \pm 0. & \pm 0. & \pm 0. & \pm 8. \\
& & $1 \%$ & $1 \%$ & $1 \%$ & $1 \%$ & $3 \%$ & $0 \%$ \\
\hline
\end{tabular}

Optimized band gap for AM1.5 from 310-1710nm

\begin{tabular}{|l|l|l|l|l|l|l|l|}
\hline $\mathrm{n}$ & $\begin{array}{l}\eta \\
(\%)\end{array}$ & $\mathrm{E}_{\mathrm{G}, 1}$ & $\mathrm{E}_{\mathrm{G}, 2}$ & $\mathrm{E}_{\mathrm{G}, 3}$ & $\mathrm{E}_{\mathrm{G}, 4}$ & $\mathrm{E}_{\mathrm{G}, 5}$ & $\mathrm{E}_{\mathrm{G}, 6}$ \\
\hline 1 & 34.9 & 1.34 & -- & -- & -- & -- & -- \\
\hline 2 & 46.9 & 1.64 & 0.98 & -- & -- & -- & -- \\
\hline 3 & 53.0 & 1.92 & 1.39 & 0.96 & -- & -- & -- \\
\hline 4 & 56.6 & 2.0 & 1.50 & 1.13 & 0.75 & -- & -- \\
\hline 5 & 59.0 & 2.16 & 1.68 & 1.34 & 1.03 & 0.74 & -- \\
\hline 6 & 59.4 & 2.34 & 1.91 & 1.6 & 1.37 & 1.15 & 0.95 \\
\hline
\end{tabular}

Optimized band gap for averaged spectrum of CREST data from 310-1710 nm

\begin{tabular}{|l|l|l|l|l|l|l|l|}
\hline $\mathrm{n}$ & $\begin{array}{l}\eta \\
(\%)\end{array}$ & $\mathrm{E}_{\mathrm{G}, 1}$ & $\mathrm{E}_{\mathrm{G}, 2}$ & $\mathrm{E}_{\mathrm{G}, 3}$ & $\mathrm{E}_{\mathrm{G}, 4}$ & $\mathrm{E}_{\mathrm{G}, 5}$ & $\mathrm{E}_{\mathrm{G}, 6}$ \\
\hline 1 & 35.0 & 1.38 & -- & -- & -- & -- & -- \\
\hline 2 & 46.3 & 1.62 & 0.98 & -- & -- & -- & -- \\
\hline 3 & 53.0 & 1.88 & 1.37 & 0.94 & -- & -- & -- \\
\hline 4 & 55.9 & 1.99 & 1.50 & 1.13 & 0.73 & -- & -- \\
\hline 5 & 57.7 & 2.22 & 1.77 & 1.47 & 1.20 & 0.96 & -- \\
\hline 6 & 59.4 & 2.30 & 1.88 & 1.59 & 1.37 & 1.15 & 0.94 \\
\hline
\end{tabular}

As it is discussed above that the short circuit current of a multi-junction solar cell is determined by the division strategy of a spectra. In order to understand the short circuit current contributed by the n-th junction, a normalized accumulative irradiance is shown in figure 1. It compares the normalized accumulative irradiance of AM1.5 and the average measured spectrum in Loughborough. It is observed that most of the irradiance energy of the spectrum measured in Loughborough CREST are between 310-1710nm. For AM1.5 spectra, beyond $2500 \mathrm{~nm}$ the energy portion from the spectra is very small which implies in wavelength range above $2500 \mathrm{~nm}$ the optimized band gap has large uncertainty as well as a limited contribution to the overall energy delivery. By the comparison between these two accumulative irradiance portion curve, it shows that if the optimized band gap for AM1.5 is beyond 1710nm this junction will contribute lower current as the realistic spectra has very low portion of energy in this wavelength range. Obviously, it is the case of the 6th junction of a solar cell. 


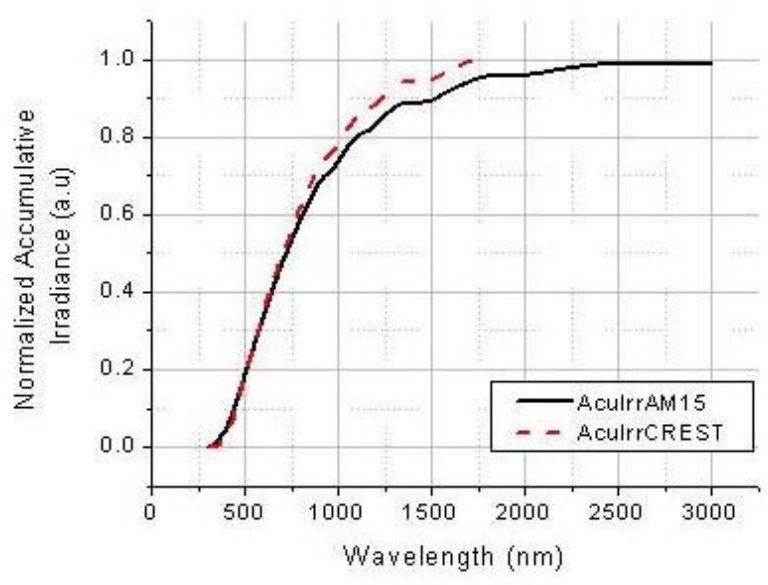

Fig. 1. Normalized accumulative irradiance of AM1.5 spectrum and the average measured CREST spectra.

\section{EXPERIMENTAL DATA}

The data used for this work is that of the entire year from August 2003 - 2004. The experimental setup is described e.g. in [2]. The measurement at CREST show a bias towards lower irradiances as shown in figure 2 . This is due to the northern climate in UK. A useful parameter, average photon energy (APE) [7] defined as the total irradiance contained in the spectrum divided by the total photon flux density, is used to characterize the spectral irradiance distribution. It shows that the mean value of APE at CREST is about $1.6 \mathrm{eV}$ but ranges from 1.3 to 2.0 eV during normal operation, i.e. it shows a very significant variation. In addition, the monthly change of the irradiance is shown in figure 3 . It shows that the monthly irradiance at CREST are all under $70 \mathrm{kWh} / \mathrm{m}^{2}$ and the maximum irradiance happened in Sept 2003 and May 2004 respectively (the relatively low values for June to August are due to some periods where the system needed to be taken down for maintenance). The accumulative irradiance for the irradiance bins are show in figure 4 . It shows that most of the irradiance energy are from $800-1000 \mathrm{~W} / \mathrm{m} 2$.

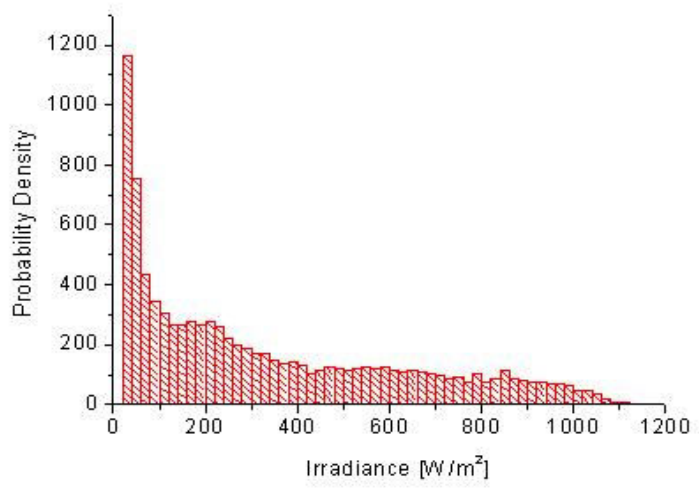

(a)

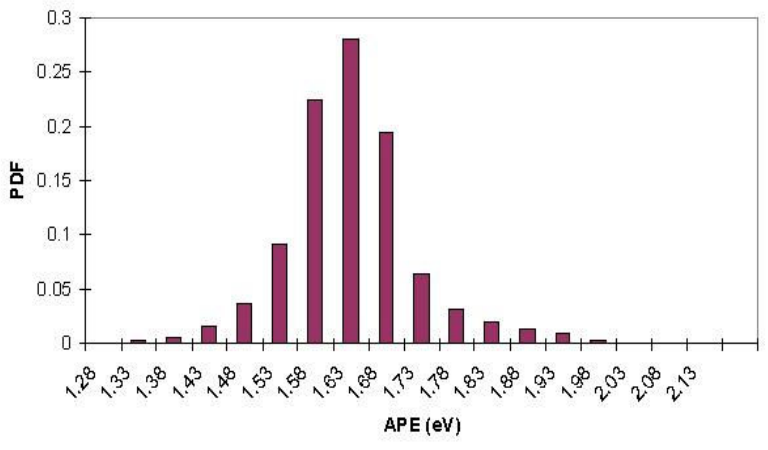

(b)

Fig. 2. The distribution of spectral irradiance (a) and PDF of APE measured at CREST (Loughborough, UK) (b).

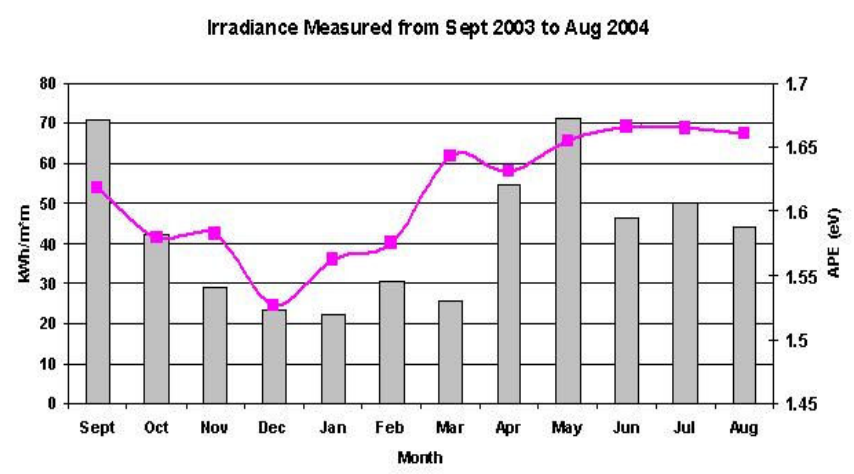

Fig. 3. Monthly irradiance changes.

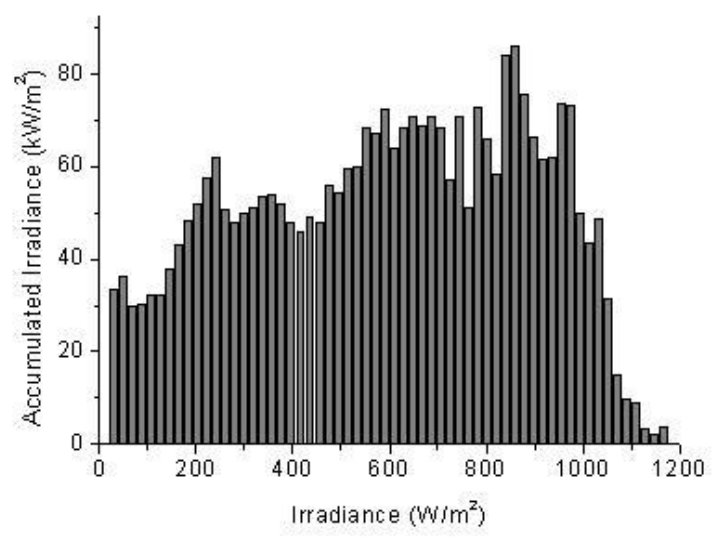

Fig. 4. Accumulated irradiance for different irradiance strength

\section{RESULTS}

Instant efficiencies and annual efficiency 
With the optimized material band gap under AM1.5, AM1.5 (310nm-1710nm) and under average measured spectrum at CREST different statistical distributions of cells' instant efficiencies over a whole year are observed. The mean values and the standard deviation of the instant efficiencies of multi-junction (from 1 to 6 ) are compared in figure 5 . The instant efficiency is defined in formula (4)

$$
\eta(t)=\frac{P(t)}{A G(t)}
$$

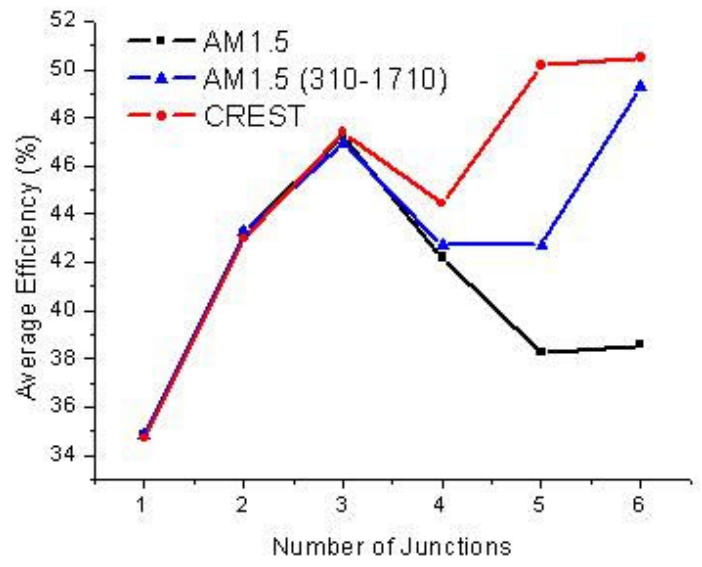

(a)

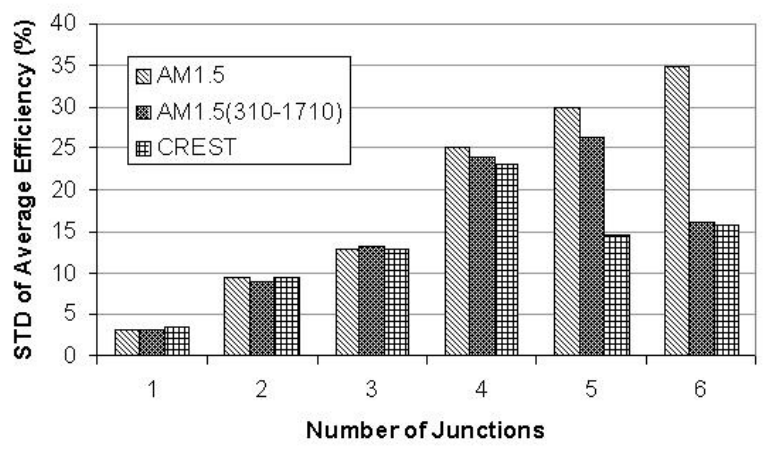

(b)

Fig. 5, (a) average efficiency of multi-junction cells optimized under different condition for the measured spectrum data in CREST (b) the variation of efficiencies of multi-junction solar cells seen due to natural variation of incident spectra expressed in terms of standard deviations of the average.

The statistical analysis shows that the range of the mean efficiency of solar cell with 1-6 stacks covers from $34 \%$ to $51 \%$. With the optimized material band gap under STC, the maximum efficiency is happen on triple junction solar cell. While with the optimized material band gap of AM1.5 (310-1710nm) and of the realistic spectrum the maximum efficiency is increasing with the increased number of junctions. The lower efficiencies observed for 4/5 junction cells optimized under AM1.5(310-1710nm) are due to the shape of the spectra and the approximation that the upper junctions absorb the entire useable wavelength. The reason for this is because the power delivery from the junction is determined by the product of Jsc and Voc assuming fill factor of unity, the rate of decrease of Jsc and the increase rate of Voc determine the maximum value of the power output with the increasing junction numbers. In figure 5 (b) it is shown that the for a cell with single to triple junctions, the standard deviation of the instant efficiencies are similar, however, to the higher number of junctions (46 ) the standard deviation of efficiencies continuously increase for the optimized junction under STC. This shows that the naturaly occurring variation of incident spectra will cause significant losses For the efficiency from the cell optimized under AM1.5 (310-1710) and realistic spectrum, the standard deviation of instantaneous efficiencies decreases compared to the case under STC and decrease from 4 junctions to 6 junctions. The reason for the low value of average efficiency of a cell with 4 junctions is possibly due to its high sensitivity to the spectral variation within the whole year in Loughborough. The average spectra and the labelled band gap (converted to wavelength) is shown in figure 6 .

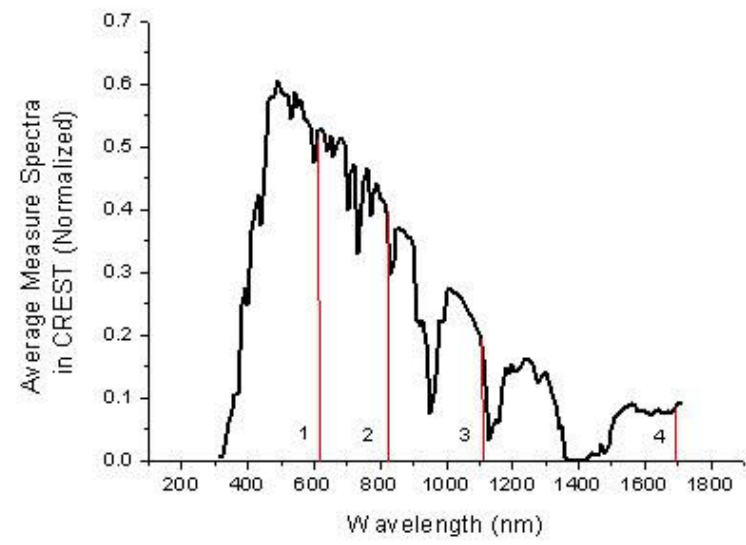

Fig. 6. The normalized average measured spectra (in CREST) and the optimized band gap (converted to wavelength) for this spectra of 4 junction cell.

The annual efficiency defined as the total energy produced by the cell per unit time (an hour) to the total incident energy per unit time as shown in formula (5) and the comparison is shown in figure 7. It shows that with 4-6 junctions, a solar cell has increasing efficiency with higher number of junctions if it optimized under realistic spectra.

$$
\eta=\frac{\sum_{i} P_{i} \Delta t_{i}}{A \sum_{i} G_{i} \Delta t_{i}}
$$




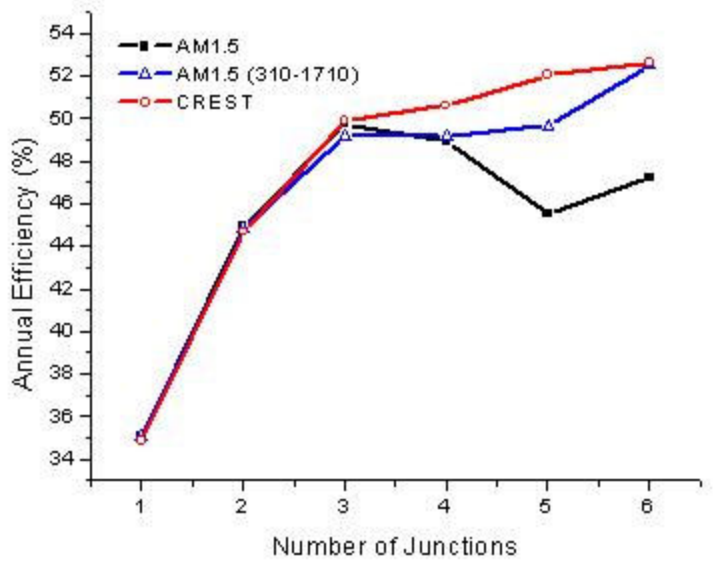

Fig. 7. Realistic annual efficiencies of multi-junction solar cell with band gaps optimized under different condition.

\section{Annual yield and performance ratio}

The normalized annual yield, the kWh per kWp and the performance ratio of the cells with stacks from 1 to 6 are compared in figure 8 below. The annual yield and the $\mathrm{kWh} / \mathrm{kWp}$ are all normalized (in percent) to the value of single junction under AM1.5. This is because the data used here are filtered spectrum. It shows that although the real annual yield from triple junction cell is comparable to $4 / 5$ junctions, due to the predicted higher power output under STC which is typically treated as peak Watts output, the $\mathrm{kWh} / \mathrm{kWp}$ of $4 / 5$ junction cells are still lower than triple junctions.

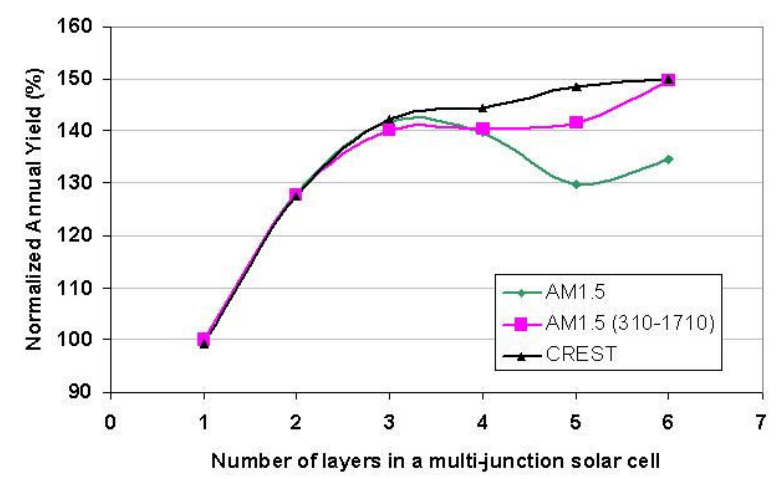

(a)

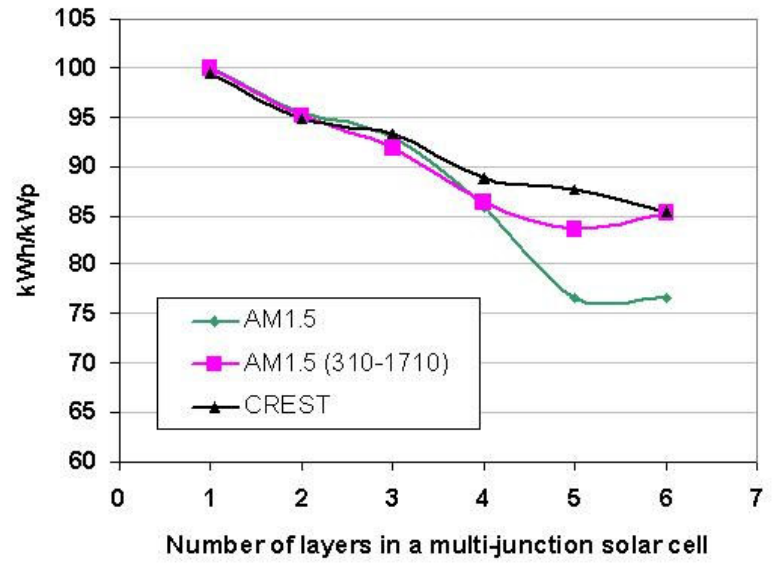

(b)

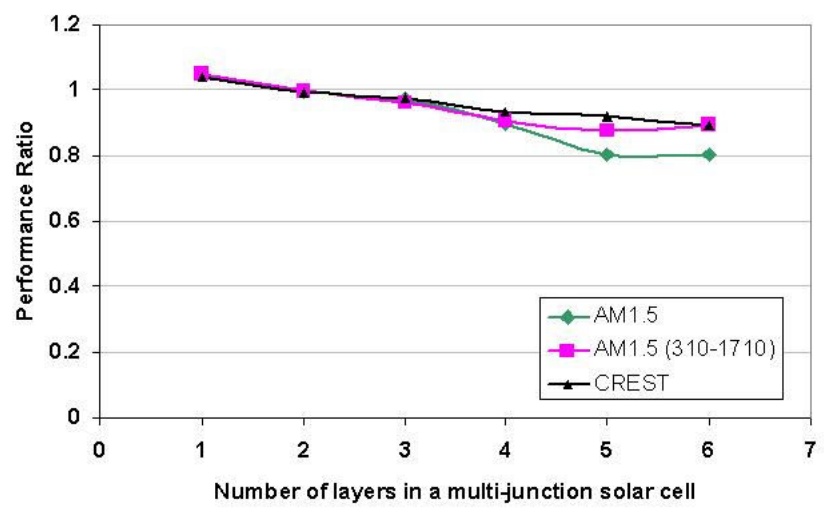

(c)

Fig. 8. Annual yield (a) and performance ratio (b) of multijunction solar cells with band gaps optimized under different condition and (c) performance ratio for the cell optimized under AM1.5 (310-1710nm) and average spectra.

\section{CONCLUSIONS}

Under a non-ideal irradiance condition, the performance of multi-junction solar cells are different from the STC/ideal condition. Due to the spectral variation, the optimal material band gap of the multi-junction will shift correspondingly. And this further affect the prediction accuracy of the solar cell performance. Therefore, the spectral deviation from STC(AM1.5) should be taken into account to optimize solar cell structures and then for the system design.

\section{REFERENCES}

[1] Marti A. Araujo GL. "Limiting efficiencies for photovoltaic energy conversion in multigap systems." Sol. Energy Mater. Sol. Cells. 43, 1996, pp. 203-222. 
[2] R. Gottschalg, T.R.Betts, D.G.Infield, M.J. Kearney. "The effect of spectral variations on the performance parameters of single and double junction amorphous silicon solar cells." Sol. Energy Mater. Sol. Cells. 85, 2005, pp. 415-428.

[3] Sarah Kurtz, Daryl Myers, W. E. McMahom, John Geisz and Myles Steiner. "A comparison of theoretical efficiencies of multi-junction concentrator solar cells." Prog. Photovolt: Res. Appl. 16, 2008, pp. 537-546.

[4] Shockely W, Queisser HJ. "Detailed balance limit of efficiency of p-n junction solar cells." J. Appl. Phys. 32, 1961 , pp. 510.
[5] H. Kiess, W. Rehwald, "On the ultimate efficiency of solar cells. " Sol. Energy Mater. Sol. Cells. 38, 1995, pp. 45-55.

[6] T. Zdanowicz, T. Rodziewicz, M. Zabkowska-Waclawek, "Theoretical analysis of the optimum energy band gap of semiconductors for fabrication of solar cells for applications in higher latitudes locations ", Sol. Energy Mater. Sol. Cells 87, 2005, pp. 757-769.

[7] Thomas R. Betts. Ph.D. Thesis. "Investigation of Photovoltaic Device Operation under Varying Spectral Conditions." 2004. Loughborough University. 